\title{
Laryngeal Response to Hypoxia in Awake Lambs during the First Postnatal Days
}

\author{
JEAN-PAUL PRAUD, IRENEJ KIANICKA, JEAN-FRANÇOIS LEROUX, AND \\ DANIEL DALLE \\ Jeremy Rill Center and Pulmonary Research Unit, Department of Pediatrics and Physiology, \\ Faculty of Medicine, University of Sherbrooke, Sherbrooke, Québec, Canada J1H 5N4
}

\begin{abstract}
We recently showed that hypoxia does not induce active expiratory glottic adduction in awake lambs more than $10 \mathrm{~d}$ old. To reconcile our results with previous data from other researchers, we hypothesized that an active expiratory glottic closure might still be part of the response to hypoxia in the very first postnatal days. The present study was undertaken to test this hypothesis. We studied 22 awake, nonsedated lambs during hypocapnic hypoxia (fraction of inspired $\mathrm{O}_{2}=0.08$ during 15 $\mathrm{min}$ ) induced during the first $72 \mathrm{~h}$ of postnatal life. We recorded airflow via a facial mask and pneumotachograph, along with the electromyographic activity (EMG) of the thyroarytenoid muscle (a glottic adductor) in 10 lambs. We also recorded the EMG of both the posterior cricoarytenoid $(n=4)$ and cricothyroid ( $n=$ 5) muscles (glottic abductors), as well as the abdominal muscles $(n=4)$. We identified typical expiratory airflow braking on the breath-by-breath computed flow-volume loop and thyroarytenoid muscle expiratory EMG as evidence of active expiratory glottic adduction. We found that hypoxia induced a biphasic ventilatory response, with an early peak and a subsequent decrease, and that active expiratory glottic adduction was absent during baseline room-air breathing and hypoxia. We also found that the glottic
\end{abstract}

ABSTRACT
It has generally been accepted that active expiratory glottic adduction is an essential component of the neonatal response to hypoxia. This expiratory flow-braking mechanism supposedly increases the end expiratory lung volume, thus optimizing the alveolar blood gas exchange. This concept was largely derived from the clinical observation of expiratory grunting in hypoxic neonates with respiratory distress syndrome (1). However, studies of the laryngeal response to hypoxia in early life have yielded conflicting results. Although previous researchers have found an active expiratory glottic adduction in response to hypoxia in neonatal lambs $(2,3)$, we recently showed that hypoxia $\left(\mathrm{FiO}_{2}=0.08\right.$ during $\left.15 \mathrm{~min}\right)$ did not enhance the expiratory EMG of the TA-a glottic adductor muscle-in 11-

Received July 20, 1994; accepted November 14, 1994.

Correspondence and reprint requests: Jean-Paul Praud, M.D., Ph.D., Department of Pediatrics, Faculty of Medicine, University of Sherbrooke, 3001 North 12th Ave., Sherbrooke, Québec, Canada J1H 5 N4.

Supported by the Medical Research Council of Canada, Grant MT 7137. Jean-Paul Praud is a scholar of the Fonds de Ia recherche en santé du Québcc. abductor phasic inspiratory and tonic expiratory EMG as well as the abdominal muscle phasic expiratory EMG, all of which were present during baseline recording, increased during hypoxia. We conclude that hypoxia does not induce expiratory glottic closure in the very first days of life in awake lambs. Apparently, the ventilatory response to hypoxia in this period already involves an increase in the inspiratory and expiratory glottic aperture, thereby facilitating the high levels of airflow created by the contracting thoracic pump muscles. (Pediatr Res 37: 482-488, 1995)

Abbreviations
CT, cricothyroid muscle
EMG, electromyographic activity
Fio $_{2}$, fraction of inspired $\mathrm{O}_{2}$
$\mathbf{P a C O}_{2}$, arterial blood $\mathrm{CO}_{2}$ tension
$\mathbf{P C A}$, posterior cricoarytenoid muscle
TA, thyroarytenoid muscle
$\mathbf{T}_{\mathbf{T A}}$, time period of enhanced TA expiratory EMG
$\dot{\mathbf{V}}_{\mathbf{E}}$, minute ventilation
$\mathbf{V}_{\mathbf{T}}$, tidal volume

to 22-d-old awake lambs (4). Although our results are in agreement with data obtained in adult life (5-7), they were obtained in 11- to 22-d-old lambs with mature peripheral chemoreceptors. We therefore hypothesized that the active expiratory glottic adduction in response to hypoxia might be a unique feature of the very early postnatal period. This hypothesis was in keeping with our demonstration that peripheral chemoreceptor activity, which is low at birth, appears to inhibit TA activity in 11- to 22-d-old lambs (4). Moreover, our hypothesis would reconcile the apparent discrepancy between our results (4) and those obtained by Coté et al. (3) in lambs younger than $3 \mathrm{~d}$.

The present study was thus conducted to test the hypothesis that hypoxic lambs in the early postnatal period react to hypoxia by actively closing the glottis during expiration. We also studied the response of glottic abductor and abdominal muscles to hypoxia so as to obtain further insights into the response to hypoxia during early life. 


\section{METHODS}

\section{Animals}

Twenty-two lambs were enrolled in the study. Because of tachypnea (more than 100 breaths $/ \mathrm{min}$ ) during baseline roomair breathing in seven, we report the results in only 15 lambs. It should be noted, however, that the laryngeal response to hypoxia was qualitatively similar in the 22 lambs studied.

The lambs that underwent surgical preparation (see below) were born in our animal quarters so that surgery could be performed in the very first hours after birth. All lambs were boarded with their mothers in our animal quarters before the experiment. On the day of the experiment, two lambs were in their first $24 \mathrm{~h}$ of postnatal life, 10 were between 24 and $48 \mathrm{~h}$ old, and three were in their third day of life. Their mean $( \pm S D)$ wcight was $4.25 \pm 2.28 \mathrm{~kg}$ (range $2.4-7.9 \mathrm{~kg}$ ). The local cthics committee for animal research at our institution approved the protocol of the study.

\section{Surgical Preparation}

The day before the experiment, 10 of the 15 lambs underwent a surgical procedure to place intramuscular electrodes. The details of the procedure have been described elsewhere (4, 8). Bricfly, under direct vision, we inserted an intramuscular bipolar electrode (enameled chrome wire, $0.7-\mathrm{mm}$ diameter, Chromel, GTSM, Castelnaudary, France) into the TA of the 10 lambs via a window cut in the thyroid cartilage. Electrodes were also inserted in other intrinsic laryngeal muscles: in the PCA (four lambs) after rotation of the larynx, through an incision made in the inferior pharyngeal constrictor; and in the CT (five lambs) (8). Another electrode was placed in the superficial oblique external abdominal muscle of four lambs (9). The leads were subcutaneously tunncled to exit on the back of the animals. The animals received one dose of antibiotics (penicillin and gentamicin) after surgery. The placement of the electrodes was confirmed by a systematic autopsy after completion of the experiment.

In 10 lambs, we also inserted a catheter into the brachial artery for arterial blood gas sampling. Blood gas values were corrected for the rectal temperature of the lamb (Mon-a-Therm 6500 , St. Louis, MO) (10).

\section{Measurement Apparatus}

The measurement apparatus used has been described in our previous studies (4). Briefly, we attached a face mask, specifically designed for each lamb, to a size 0 pncumotachograph (Hewlett-Packard 21070B, plus Hewlett-Packard 8815A respiratory integrator, Hewlett-Packard, Palo Alto, CA). The $\mathrm{Fio}_{2}$, delivered through a $\mathrm{T}$ piece at a constant gas flow, can bc switched between $0.08,0.21$, and 1.00 in less than $1 \mathrm{~s}(21049$ and P314 Collins valves). We used a mass spectrometer (Perkin-Elmer MGA 1100) to continuously measure the $\mathrm{Fio}_{2}$ delivered to the lamb and to monitor end-tidal $\mathrm{CO}_{2}$ at the mask. The laryngeal and abdominal muscle EMG signals were amplified and 30- to 1000-Hz band-pass filtered (Grass P511 AC preamplifier, 7DA DC driver amplifier, Grass Instrument Co., Quincy, MA) before undergoing a 100 -ms moving time aver- aging (Department of Electronics, Faculty of Medicine, University of Sherbrooke, Qucbec, Canada). Our integrator has parallel outputs for a chart recorder and a computer. An cight-channel polygraph (Grass 7D, Grass Instrument Co.) recorded the instantaneous airflow, the $\mathrm{V}_{\mathrm{T}}$, the $\mathrm{FiO}_{2}$, and the raw and integrated EMG signals. An IBM-compatible microcomputer (Televideo TeleCAT-286) analyzed the instantaneous airflow, the integrated EMG signals, and the $\mathrm{FiO}_{2}$ at a $40-\mathrm{Hz}$ sampling rate. The collected data were stored on disk for further analysis.

\section{Design of the Study}

The design of the study protocol allowed us to infer the role of hypoxia on TA EMG activity in awake lambs in the very first postnatal days. We could also study the coordination between the TA muscle, glottic abductor muscles, and abdominal muscles during hypoxia at this early age. Also, we could cvaluate the differential role of central and peripheral chemoreceptors during hypoxia. This last evaluation was accomplished $l$ ) by having each lamb inhale pure $\mathrm{O}_{2}$ during five inspirations (Dejours' test), thereby transiently withdrawing the peripheral chemoreceptor function; and 2) by comparing in the same lamb $(n=4)$ the responses to hypocapnic and isocapnic hypoxia.

Our study was done with each lamb positioned in a sling during quict wakefulness. After applying the face mask and carefully positioning the head, we gave each lamb at least 10 min to adjust to the mask. Between the two hypoxic runs, we allowed the lambs sufficient time to regain baseline prchypoxic ventilation and arterial blood gas values.

Hypocapnic hypoxia test. The hypocapnic hypoxia test has becn described elsewhere (4). Briefly, we recorded baseline room-air ventilation for $3 \mathrm{~min}$, before abruptly switching the animal to $0.08 \mathrm{FiO}_{2}$ for a hypoxic period of $15 \mathrm{~min}$. During that 15-min hypoxic period, we performed a Dejours' test at the 6and 12 -min marks. We then abruptly switched the animal from $0.08 \mathrm{FiO}_{2}$ back to room air for $3 \mathrm{~min}$ of recording. The entire test was completed in $21 \mathrm{~min}$.

Isocapnic hypoxia test. The design of this second test was identical to that just described, except that we carcfully maintained the isocapnia by continually adding $\mathrm{CO}_{2}$ to the inspiratory gas mixture. We adjusted the amounts of added $\mathrm{CO}_{2}$ in light of the continual monitoring of end-tidal $\mathrm{CO}_{2}$ and the measuring of $\mathrm{PaCO}_{2}$ at 3-min intervals.

\section{Data Analysis}

Response to hypoxia. We computed $\dot{\mathrm{V}}_{\mathrm{E}}, \mathrm{V}_{\mathrm{T}}$, and breathing frequency for each breath. Avcrages were calculated over $15 \mathrm{~s}$ during the baseline recording; during hypoxia at the moment of the peak ventilatory response; at the 6-, 9-, 12-, and 15-min marks of hypoxia; and finally, 2 min after the return to roomair breathing. We carefully observed the TA EMG, together with the EMG of the other studied muscles, throughout cach experimental procedure. We looked for simultaneous expiratory airflow braking in the shape of the flow-volume curves computed breath by breath during the above-defined 15-s epochs in each lamb. 

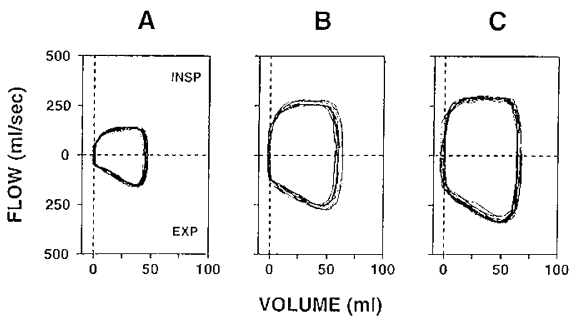

Figure 1. Breath-by-breath computed flow-volume curve obtained in a lamb during baseline room-air breathing $(A)$ and at the 6 min- $(B)$ and 12 min- $(C)$ marks of hypoxia. Note the absence of an abrupt decrease in the expiratory flow that could have suggested airflow braking by glottic closure.

Response of TA and other respiratory muscles to Dejours' test. For each Dejours' test conducted during hypoxia, we calculated the $\mathrm{T}_{\mathrm{TA}}(\mathrm{s})$ after $\mathrm{O}_{2}$ inhalation. We also observed the response to $\mathrm{O}_{2}$ inhalation of the other muscles under study. In addition, we examined the influence of $\mathrm{PaCO}_{2}$ by comparing the $\mathrm{T}_{\mathrm{TA}}$ obtained during the hypocapnic and isocapnic hypoxia tests in the four lambs studied in both conditions.

\section{Statistical Analysis}

The ventilatory parameters obtained during the hypocapnic hypoxia tests were compared via an analysis of variance for repeated measures, completed by contrast comparison of the means (Superanova, Abacus Concepts, Berkeley, CA).

$p<0.05$ was considered significant.

\section{RESULTS}

\section{Baseline Room-Air Breathing}

Ventilation. During baseline room-air breathing for the 15 lambs, mean $\dot{V}_{\mathrm{E}}$ was $724 \pm 168 \mathrm{~mL} \cdot \mathrm{kg}^{-1} \cdot \mathrm{min}^{-1}$ (mean \pm $\mathrm{SD}$ ), mean $\mathrm{V}_{\mathrm{T}}$ was $12.9 \pm 3.1 \mathrm{~mL} \cdot \mathrm{kg}^{-1}$, and mean breathing frequency was $59 \pm 17 \mathrm{~min}^{-1}$. Arterial blood gas values in the 10 lambs with an arterial line were: arterial blood $\mathrm{O}_{2}$ tension $=$ $10.1 \pm 1.6 \mathrm{kPa} ; \mathrm{PaCO}_{2}=5.7 \pm 0.6 \mathrm{kPa}$; and $\mathrm{pH}=7.37 \pm$ 0.06 . None of the 15 lambs showed any expiratory airflow braking on the airflow traces or the breath-by-breath computed flow-volume curves (Fig. 1A).

TA muscle activity. The TA EMG was continuously recorded in 10 lambs. During baseline room-air breathing, the TA was largely inactive in eight lambs, apart from the swallowing movements (Figs. $2 A$ and $3 A$ ). In the other two lambs, a small-amplitude phasic inspiratory EMG was consistently recorded from the TA electrode. No TA phasic expiratory EMG was observed in any of the 10 lambs.

Glottic abductor muscle and abdominal muscle activity. In the four lambs whose PCA (glottic abductor muscle) was studied and in the five lambs whose CT (synergistic to the PCA for the inspiratory glottic abduction) was studied, we observed consistent phasic inspiratory and tonic expiratory EMG in both glottic muscles (Figs. $2 A$ and $3 A$ ). In the four lambs whose external oblique abdominal muscle was studied, a phasic expiratory abdominal muscle EMG was consistently observed, the amplitude varying with the body movements (Fig. $3 A$ ).

\section{A $\quad$ B}

TA

$\int T A$

$\mathrm{FiO}_{2}$

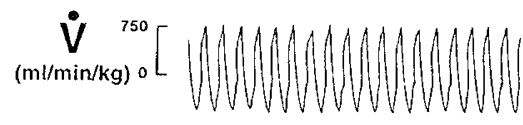

CT

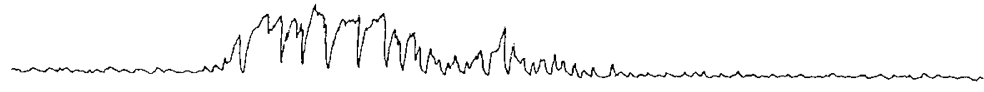

$0.08|1|$

0.08
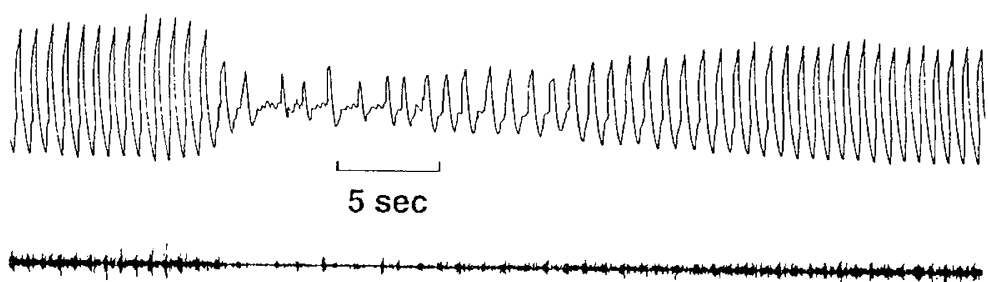

SCT munnummum

MWMWMWM

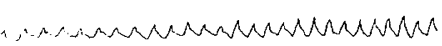

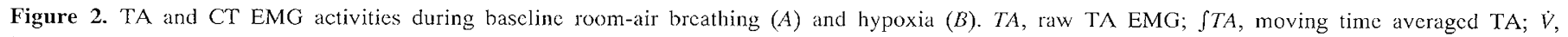

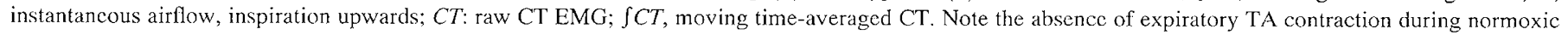

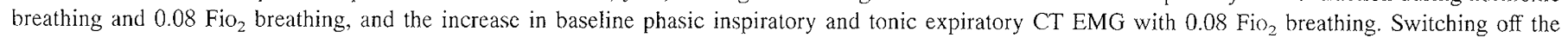

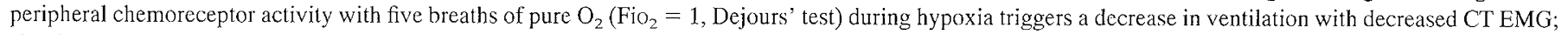
simultaneously, an expiratory airflow braking related to active glottic adduction (see TA traces) is observed. 


\section{PCA}

JPCA nnmunummun

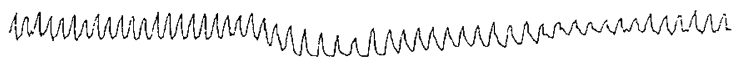
$\mathrm{FiO}_{2}$ กาmกm 0.21

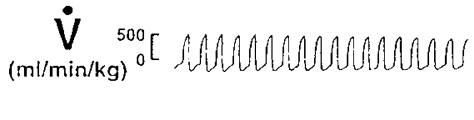

ABD
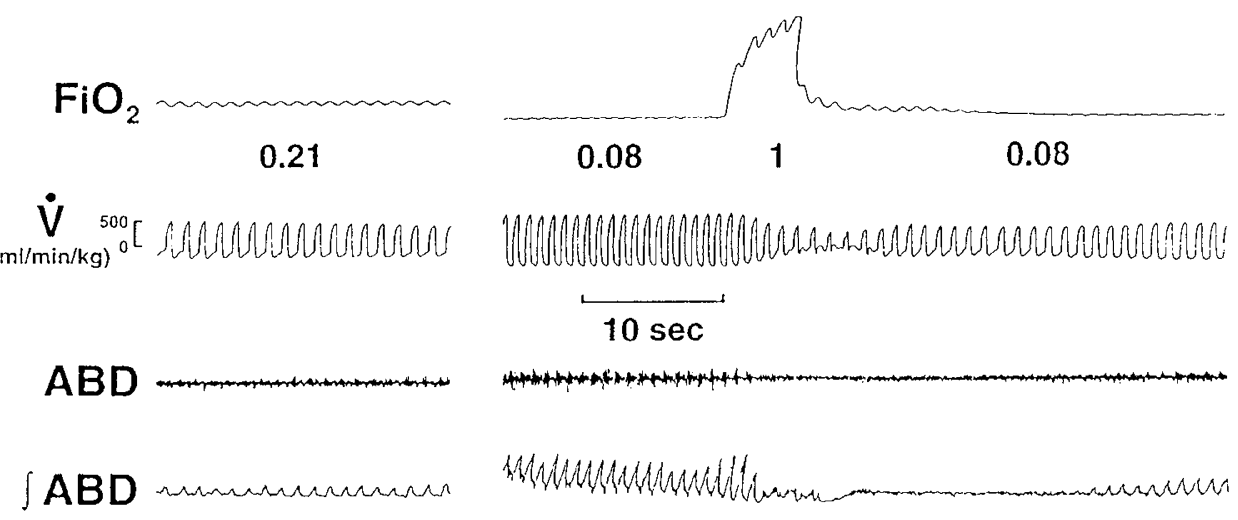

$10 \mathrm{sec}$

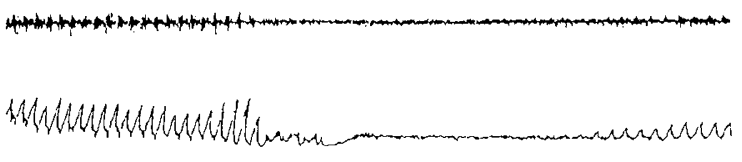

Figure 3. TA, PCA, and abdominal muscle EMG activities during baseline room-air breathing $(A)$ and hypoxia $(B)$. See Figure 2 for definition of abbreviations. $P C A$, raw PCA EMG; $\int P C A$, moving time-averaged PCA; $A B D$, raw abdominal muscle EMG; $\int A B D$, moving time-averaged ABD. During baseline room-air breathing, while TA contraction is absent, PCA phasic inspiratory and tonic expiratory EMG activities are present and ABD phasic expiratory EMG is recorded. Hypoxia $\left(\mathrm{FiO}_{2}=0.08\right)$ enhances PCA and ABD EMG activities, but no active expiratory glottic adduction is observed. On the contrary, switching off the peripheral chemoreceptor activity with five breaths of pure $\mathrm{O}_{2}\left(\mathrm{FiO}_{2}=1\right.$, Dejours' test $)$ triggers a decrease in ventilation with decreased $\mathrm{PCA}$ and $\mathrm{ABD}$ EMG, and TA expiratory contraction with expiratory airflow braking for several respiratory cycles.

\section{Hypoxic Breathing}

Ventilation. Results of the hypocapnic hypoxic test, completed in all the lambs, showed a diphasic $\dot{\mathrm{V}}_{\mathrm{E}}$ response to hypocapnic hypoxia, in the 15 awake, 1 - to 3-d-old lambs; that is, an early maximum in the first 3 min of hypoxia followed by a decrease to a plateau. During the entire hypoxic period, however, $\dot{V}_{E}$ was significantly higher than the prehypoxic value (Fig. 4). Both the $\mathrm{V}_{\mathrm{T}}$ and breathing frequency during the hypoxic period had a time course similar to that of hypocapnic hypoxia-an early maximum and a subsequent decreasealthough the breathing frequency tended to be more sustained than $\mathrm{V}_{\mathrm{T}}$ (Fig. 4). Blood gas measurements at the 6-min mark of hypoxia in all 10 lambs with an arterial line yielded the following mean values: arterial blood $\mathrm{O}_{2}$ tension $=2.7 \pm 0.5$ $\mathrm{kPa} ; \mathrm{PaCO}_{2}=4.6 \pm 0.5 \mathrm{kPa}$; and $\mathrm{pH}=7.47 \pm 0.06$.

The response of the four lambs studied during isocapnic hypoxia appeared to be somewhat higher and more sustained than that occurring during hypocapnic hypoxia. The $\dot{\mathrm{V}}_{\mathrm{E}}$ response to an $\mathrm{Fio}_{2}$ of 0.08 for 15 min during both hypocapnia and isocapnia is illustrated in Figure 5.

TA muscle activity and flow-volume curves. Our systematic and careful examination of the EMG signals throughout the hypocapnic hypoxic test consistently showed no expiratory recruitment of the TA in any of the 10 lambs (Figs. $2 B$ and $3 B$ ). Moreover, close observation of the flow traces and computed flow-volume loops of the 15 lambs showed that expiratory flow braking was absent throughout the 15 -min hypoxic test in all 15 lambs (Fig. $1 B$ and $C$ ). As for the TA inspiratory phasic EMG, if it was present during baseline room-air breathing (two lambs), it was enhanced during hypoxia.

The results were qualitatively similar during isocapnic hypoxia, for both the TA in the three lambs and the flow-volume loop in the four lambs studied in both hypo- and isocapnic hypoxic conditions.

Glottic abductor and abdominal muscles. During hypoxia, consistent enhancement of PCA (four lambs) and CT (five lambs) EMG was observed for both the inspiratory phasic and tonic expiratory EMG (Figs. $2 B$ and $3 B$ ). Also, in the four lambs whose abdominal muscle EMG were studied, we observed a consistent increase in abdominal muscle expiratory phasic EMG (Fig. 3B).

Response to Dejours' test during hypoxia. In the 15 lambs during hypocapnic hypoxia, the ventilation decreased within 3 to $4 \mathrm{~s}$ after the inhalation of pure $\mathrm{O}_{2}$. The decrease in ventilation varied, however, from one lamb to another: whereas in 12 lambs the Dejours' test induced a mild decrease in $V_{\Upsilon}$ as wcll as in breathing frequency, in three lambs we observed a central apnea (duration of 3 to $10 \mathrm{~s}$ ). Concurrent with the decrease in ventilation, TA expiratory EMG appeared in five of the seven lambs; it then progressively faded when the ventilation re- 

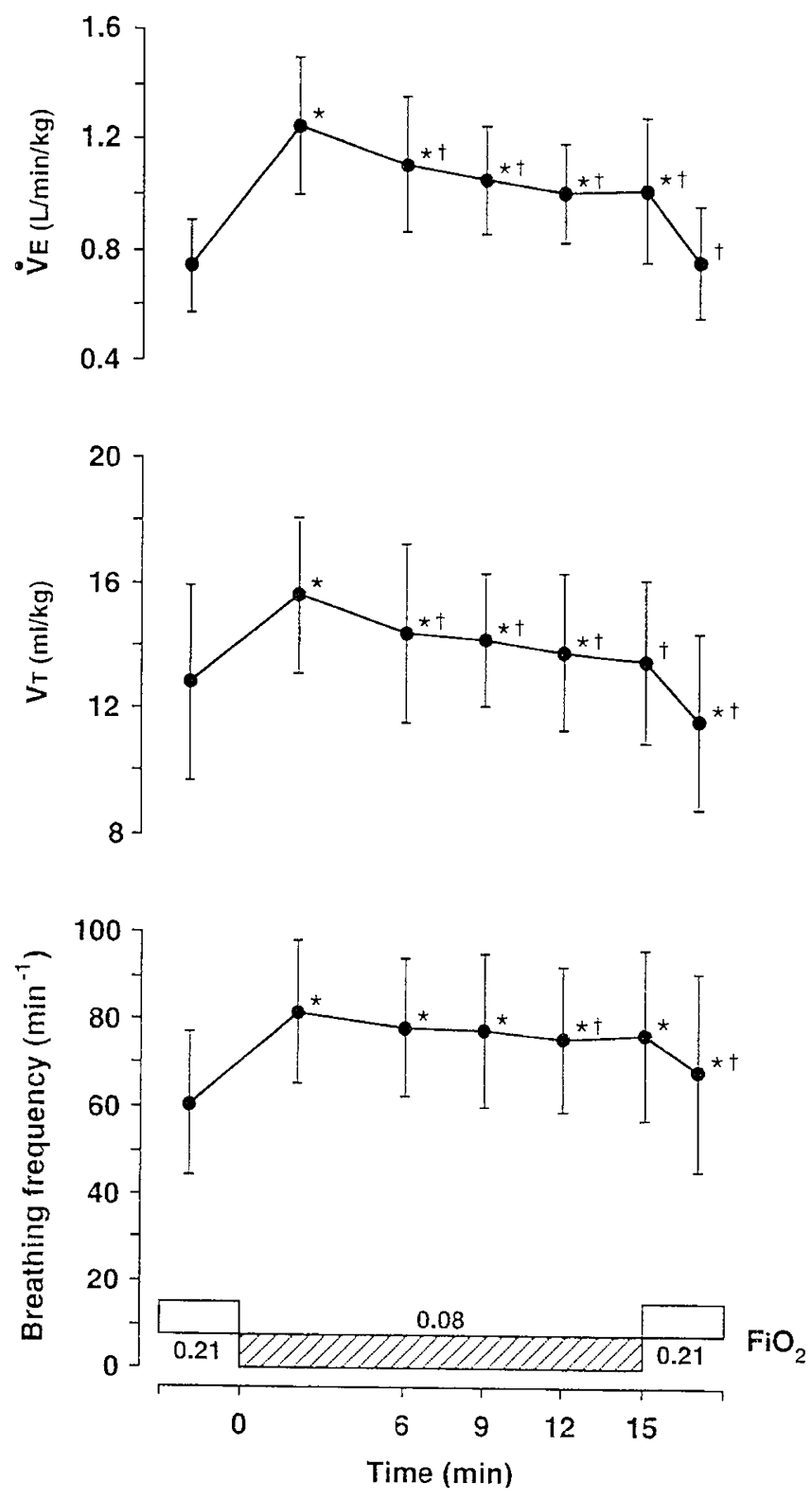

Figure 4. Ventilatory responsc to $15 \mathrm{~min}$ hypocapnic hypoxic breathing $\left(\mathrm{FiO}_{2}=0.08\right)$ in 15 awake lambs during the first 3 postnatal days. Bars $=\mathrm{SD}$. $" p<0.05$ us baseline; $\uparrow p<0.05$ vs peak.

gained the pre-Dejours' test level (Figs. $2 B, 3 B$, and $6 A$ ). Also, tonic TA EMG was observed throughout the central apnea in two of the three lambs, changing to expiratory EMG for the first few breaths after resumption of breathing. The time period $\mathrm{T}_{\mathrm{TA}}$ of enhanced TA expiratory (and continuous, when present) EMG for the 10 lambs was $12.9 \pm 10 \mathrm{~s}$ (range 0 to 33 s). Close observation of the airflow trace and the breath-bybreath computed flow-volume loop showed that an expiratory flow braking paralleled the presence of TA expiratory EMG (Figs. $2 B, 3 B$, and $6 A$ ).

During isocapnic hypoxia, the decrease in ventilation in response to the Dejours' test was consistently less marked than that which occurred during hypocapnic hypoxia in the four lambs studied in both conditions. Similarly, the TA response was absent or markedly reduced during isocapnic hypoxia

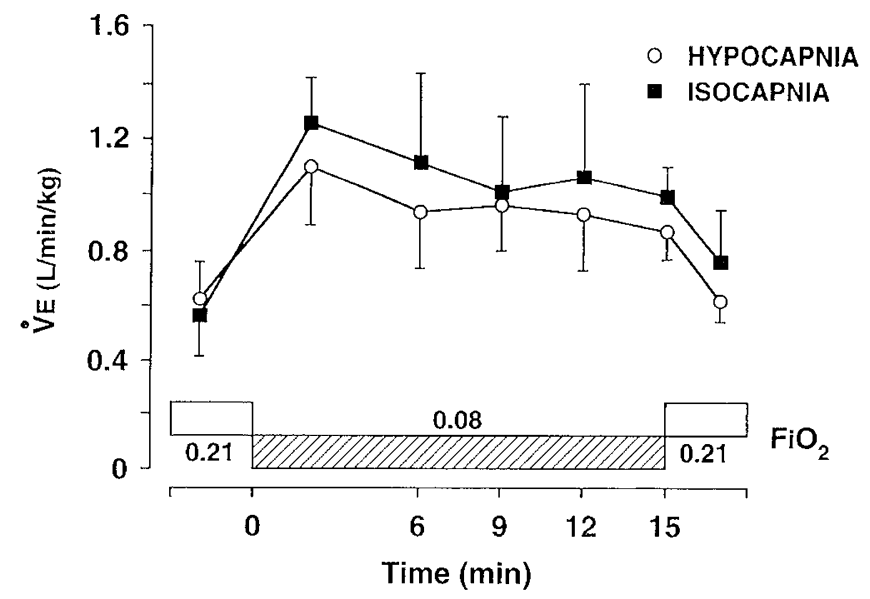

Figure 5. Ventilatory response to $15 \mathrm{~min}$ of hypoxic breathing $\left(\mathrm{FiO}_{2}=0.08\right)$ in four awake lambs in hypocapnic and isocapnic conditions. Bars $=\mathrm{SD}$.

$\left(\mathrm{T}_{\mathrm{TA}}=6.3 \pm 3 \mathrm{~s}\right)$ compared with the response of the same lambs during hypocapnic hypoxia ( $\mathrm{T}_{\mathrm{TA}}=24.3 \pm 8 \mathrm{~s}$ ) (Fig. 6).

The decreased ventilation in response to the Dejours' test during hypoxia was accompanied by a parallel decrease in PCA and CT EMG for both the inspiratory and expiratory components (Fig. $2 B$ and $3 B$ ). When central apnea and continuous TA EMG were present, both PCA and CT EMG were absent throughout central apnea. Although the inspiratory activity of both muscles progressively increased with resumption of breathing, the disappearance of TA expiratory EMG led to a resumption of tonic expiratory EMG of both the PCA and $\mathrm{CT}$ (Figs. $2 B$ and $3 B$ ).

A decrease in the abdominal muscle EMG was also observed in response to the Dejours' test in the four lambs undergoing this testing. This decrease paralleled the ventilatory response to Dejours' test (Fig. 3B). During central apnea, no abdominal muscle EMG was recorded in any of the four lambs.

\section{DISCUSSION}

The striking finding of this study is that, contrary to current thinking, hypoxia does not lead to active expiratory airflow braking in awake, nonsedated lambs during the first 3 postnatal days.

It has been commonly stated that the fight against hypoxia during the first days of life relies primarily on active expiratory airflow braking. This hypothesis first originated with the audible expiratory grunting heard in hypoxic preterm newborns during the respiratory distress syndrome (1); it was later supported by results from studies of the early postnatal period in mammals, during both normoxic and hypoxic breathing. First, an active expiratory airflow laryngeal braking was recorded during room-air breathing in premature (11) and term (12-14) humans, and more recently in premature lambs delivered by caesarean section (15). In these studies, however, the active expiratory airflow laryngeal braking was clearly observed only during the first minutes after birth; it disappeared thereafter. Second, hypoxia was reported to enhance TA expiratory EMG in tracheostomized lambs during quiet sleep (2) or to trigger an expiratory airflow braking in lambs during their first $3 \mathrm{~d}$ of life (3). At this point, the common understanding of the response to 


\section{A}

TA
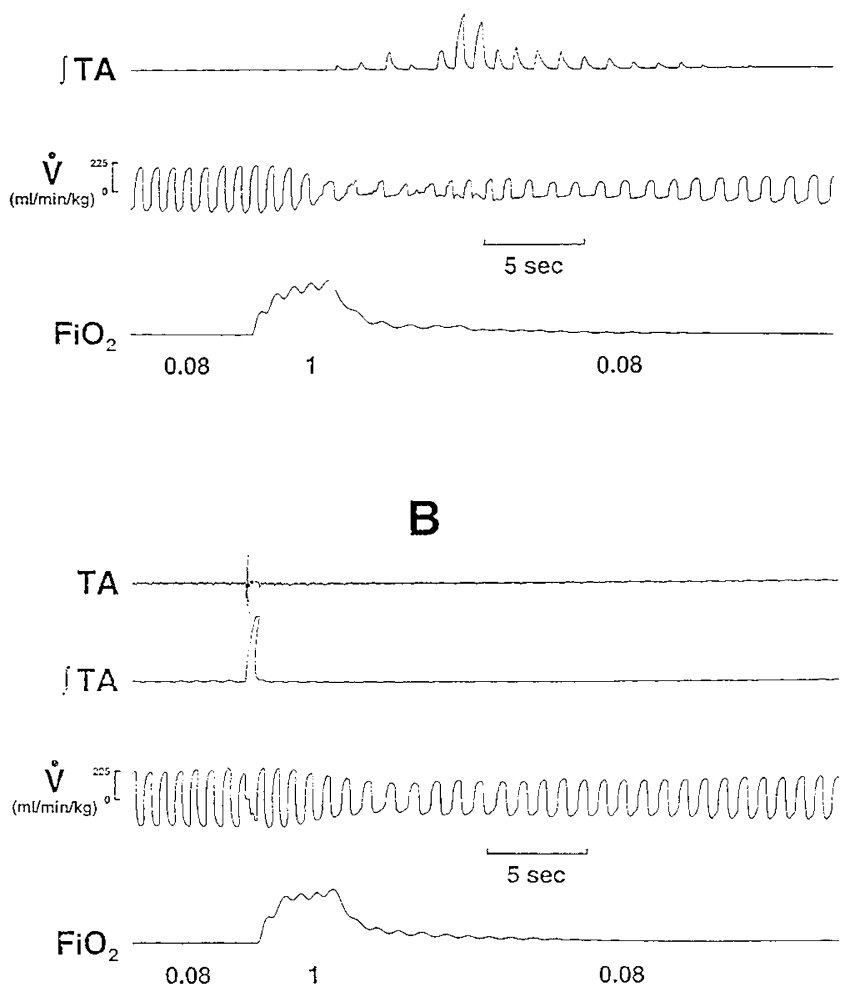

Figure 6. Ventilatory and TA response after pure $\mathrm{O}_{2}$ inhalation during hypocapnic hypoxia $(A)$ and isocapnic hypoxia $(B)$. Abrupt fall in ventilation with marked enhancement of TA EMG is only observed in hypocapnic hypoxia.

hypoxia during the early postnatal period was that, by actively closing the glottis, the newborn mammal induced an expiratory airflow braking that eventually served both to increase the end-expiratory lung volume and to enhance the oxygen extraction by the pulmonary blood $(3,16)$. With its involvement of the small intrinsic laryngeal muscles and its low cost in terms of energy requirements, this mechanism-the so-called intrinsic positive end expiratory pressure-appeared particularly suited to the hypoxic newborn mammal in the first hours of life $(3,16)$.

Recent data from our laboratory, however, challenge this concept. Indeed, we have shown that hypoxia in awake, nonsedated lambs more than $10 \mathrm{~d}$ old does not lead to active expiratory glottic adduction (4). In the same study, by partitioning the effects of the various controllers of the TA activity during hypoxia, we were able to show that the stimulation of the peripheral chemoreceptors in lambs more than $10 \mathrm{~d}$ old has an inhibitory influence on expiratory TA EMG, as reported in adult mammals as well (7). To reconcile our results in awake lambs more than $10 \mathrm{~d}$ old (4) with the results obtained in awake lambs less than $72 \mathrm{~h}$ old (3), we hypothesized that the postnatal maturation of the peripheral chemoreceptor function might explain both the more sustained ventilatory response to hypoxia and the disappearance of the active glottic adduction enhancement by hypoxia (4).

On the contrary, the present data drawn from a direct recording of the TA-a representative glottic adductor mus- cle-show that hypoxia does not lead to active expiratory glottic adduction in awake, nonsedated, very young lambs. Our data for lambs at different postnatal ages (present study and 4) and other investigators' data for adult mammals $(5,6)$ suggest that from the beginning of postnatal life and into adult life mammals do not use active expiratory glottic adduction to fight against hypoxia. However, because TA expiratory activity has been shown to be invariably present in nonsedated puppies during room-air breathing (17), the absence of TA activity enhancement by hypoxia needs to be confirmed in newborn mammals that are less mature than the lamb at birth.

It has been previously reported that the laryngeal response in hypoxia involves an inspiratory and expiratory glottic abduction that facilitates high levels of airflow in both respiratory phases. Indeed, an increased active inspiratory glottic abduction has been observed during hypoxia in awake and slecping dogs (5), adult decerebrate cats (18), and awake humans (19-21). In the present study, we observed that hypoxia increases inspiratory phasic EMG in both the PCA (the glottic abductor) and CT [synergistic to the PCA for the inspiratory glottic abduction (22)], in agreement with those previous results. Moreover, our observation that in hypoxia, when TA EMG is absent, the expiratory tonic EMG activity of both PCA and $\mathrm{CT}$ is enhanced suggests that the laryngeal aperture is increased during expiration with hypoxia compared with normoxic breathing. Previous findings by other investigators showed that hypoxia does induce a glottic widening, not only in inspiration, but also in expiration $(5,6,18-20)$. Apparently, expiratory widening of the glottis, together with the increase in the expiratory phasic EMG of the abdominal muscles, constitutes a well-coordinated response to hypoxia that is already functional at birth in lambs and is qualitatively identical to the response previously reported by us in lambs more than $10 \mathrm{~d}$ old (9).

Finally, our observations shed some light on the role of the various controllers of the laryngeal muscles during the first days of life. The unmasking of TA expiratory EMG-or even the continuous EMG when apnea was observed-by transient inhalation of pure $\mathrm{O}_{2}$ (Dejours' test) during hypocapnic hypoxia suggests that the stimulation of the central inspiratory drive by the peripheral chemoreceptors themselves in newborn lambs inhibits the glottic adductor muscles. Similarly, the decrease-and even the disappearance when apnea was present - of both the PCA and CT activity after the Dejours' test in hypoxia suggests that the stimulation of the peripheral chemoreceptors is responsible for an increased phasic and tonic EMG of glottic abductor muscles. Moreover, the differences in the results obtained in hypocapnic hypoxia and isocapnic hypoxia suggest that the decreased afferents from the central chemoreceptors in the hypocapnic run stimulate the expiratory glottic adduction but inhibit the contraction of the glottic abductors. The above results are qualitatively similar to the results we obtained in awake, nonsedated lambs more than 10 d old, although the effect of the peripheral chemoreceptors during hypoxia is obviously much less during the first postnatal days (23). Our results do not permit us to discuss the potential participation of the potent vagal influences (24) in the inhibi- 
tion of the active expiratory glottic adduction during hypocapnic hypoxia.

The reasons for the discrepancies between the present data and those obtaince in two previous studies in lambs $(2,3)$ are not clear. The presence of a fencstrated tracheostomy tube and/or the different sleep statc (quiet sleep versus wakefulness) could account for the cnhanced TA activity during expiration in the study by Johnson and Fewcll (2). On the other hand, the expiratory airflow braking observed in some lambs during hypoxia by Coté et al. (3) might well be due to the postinspiratory activity of the diaphragm. Although our study was not designed to answer this question, recent data obtained in kittens render such explanation possible (25).

In conclusion, our results show that hypoxia, with either hypocapnia or isocapnia, is not responsiblc for an active expiratory glottic closure in lambs during the very first days of life. Conversely, the response to hypoxia during this early period in lambs involves active glottic abduction during both inspiration and expiration. As for the expiratory grunting manifested by the preterm neonate during the respiratory distress syndrome, preliminary results from our laboratory indicate that it could be related to the excess of pulmonary fluid known to be present in this situation (26).

Acknowledgments. The authors thank Carole Jacques for secretarial assistance and Bruno Gagne for technical assistance.

\section{REFERENCES}

1. Harrison VC, Heese II de V, Klein M 1968 The significance of grunting in hyaline membrane discasc. Pediatrics 41:549-559

2. Johnson P', Fewell JE 1983 Further evidence for the existence of a pulmonary respiratory "oscillator" in early postnatal life. In: Schlaffe ME, Koepchen HP, Sce WR (eds) Central Neurone Environment. Springer-Verlag, Berlin, pp 147-156,

3. Coté A, Yunis K, Blanchard PW, Mortola JP, Bureau MA 1988 Dynamies of breathing in the hypoxic awake lamb. J Appl Physiol 64:354-359

4. Praud JP, Canct E, Burcau MA 1992 Chemoreceptor and vagal influences on thyroarytenoid muscle activity in awake lambs during hypoxia. J Appl Physiol $72: 962-969$

5. Fngland SJ, I Harding R, Stradling JR, Phillipson EA 1986 Laryngeal muscle activities during progressive hypercapnia and hypoxia in awake and sleeping dogs. Respir Physiol 66:327-339
6. Insalaco G, Kuna ST, Cibclla F, Villeponteaux RD 1990 Thyroarytenoid muscle activity during hypoxia, hypcrcapnia, and voluntary hyperventilation in humans. J Appl Physiol 69:268-273

7. Widdicombe JG 1992 Chemoreceptor control of the upper airway. Respir Physiol $87: 373-381$

8. Kianicka I, Lcroux JF, Praud JP 1994 Thyroarytenoid muscle activity during hypocapnic central apncas in awake non-sedated lambs. J Appl Physiol 76:1262-1268

9. Praud JP, Canet E, Kianicka I, Gautticr C, Bureau MA 1993 Vagal and chemoreceptor influences on abdominal muscle activity in awake lamb during hypoxia. J Appl Physiol 74:1689-1696

10. Andritsch RF, Muravchik S, Gold MI 1981 Temperature correction of arterial blood-gas parameters: a comparative review of methodology. Anesthesiology 55:311-316

11. Lindroth M, Johnson B, Ahlstrom H, Svenningsen NW 1981 Pulmonary mechanics in early infancy. Subclinical grunting in low-birth-weight infants. Pediatr Res 15:979-984

12. Kosch PC, Stark AR 1984 Dynamic maintenance of end-expiratory lung volume in full-tcrm infants. J Appl Physiol 57:1126-1133

13. Mortola JP 1987 Dynamics of breathing in newborn mammals. Physiol Rev 67:187233

14. Fisher JT, Mortola JP, Smith JB, Fox GS, Wecks S 1982 Respiration in newborns. Development of the control of breathing. Am Rev Respir Dis 125:650-657

15. Hutchison AA, Wozniak JA, Choi HG, Conlon M, Otto RA, Abrams RM, Kosch PC 1993 Laryngeal and diaphragmatic muscle activities and airflow patterns after birth in premature lambs. J Appl Physiol 75:121-131

16. Zamel D, Revow M, England S 1989 Expiratory airflow patterns and gas exchange in the newborn infant: results of model simulations. Respir Physiol 75:19-27

17. England SJ, Kent G, Stogryn HA 1985 Laryngeal muscle and diaphragmatic aclivities in conscious dog pups. Respir Physiol 60:95-108

18. Zhou D, Huang Q, St. John WM, Bartlett Jr D 1989 Respiratory activities of intralaryngeal branches of the recurrent laryngeal nerve. J Appl Physiol 67:11711178

19. Brancatisano TP, Dodd DS, Engel LA 1986 Responses of the posterior cricoarytenoid and alae nasi muscles to increased chemical drive in man. Respir Physiol 64:177-189

20. Kuna ST, Day RA, Insalaco G, Villeponteaux RD 1991 Posterior cricoarytenoid activity in normal adults during involuntary and voluntary hyperventilation. J Appl Physiol 70:1377-1385

21. Weatley JR, Brancatisano A, Engel LA 1991 Cricothyroid muscle responses to increased chemical drive in awake normal bumans. J Appl Physiol 70:2233-2241

22. Konrad HR, Rattenborg CC 1969 Combined action of laryngeal muscles. Acta Otolaryngol 67:646-649

23. Caroll JL, Burcau MA 1987 Decline in peripheral chemoreceptor excitatory stimulation during acute hypoxia in the lamb. J Appl Physiol 63:795-802

24. Brian AC, Bowes G, Maloncy JE 1986 Control of breathing in the fetus and the newborn. In: Cherniak NS, Widdicombe JG (eds) Handbook of Physiology, Section 3: The Respiratory System, Vol II: Control of Breathing, Part 2. American Physiological Society, Washington, DC, pp 621-647

25. Bonora M, Boulé M, Gautier H 1992 Diaphragmatic and ventilatory responses to alveolar hypoxia and hypercapnia in conscious kittens. J Appl Physiol 72:203-210

26. Praud JP, Kianicka I, Leroux JF, Gagne B 1993 Active expiratory glottic adduction due to oleic acid induced lung edema in non-sedated lambs. Am Rev Respir Dis 147:A950 